\title{
Monstrua y subalterna: la resistencia en "Subasta" (2018), de María Fernanda Ampuero'
}

\author{
Monster and Subaltern: Resistance in María Fernanda Ampuero's "Subasta" \\ (2018)
}

\author{
Sara Bolognesi ${ }^{2}$ y Alena Bukhalovskaya ${ }^{3}$
}

\begin{abstract}
Resumen
Este artículo aborda la lectura del cuento "Subasta" (2018) de la escritora ecuatoriana María Fernanda Ampuero, desde la perspectiva de la subalternidad, la monstruosidad y la abyección. Estos temas se integran en una línea prolífica de la literatura contemporánea que busca cuestionar los grandes discursos del poder, construidos como inamovibles e incuestionables, en torno a conceptos como la familia, el género y la infancia, con el fin de deconstruirlos para evidenciar su fragilidad, inestabilidad y parcialidad. Este tipo de textos trata de mostrar la vulnerabilidad propia de los cuerpos humanos, que se encuentran expuestos a los otros y, por tanto, a la violencia. La distribución del discurso en sí es represiva, ya que crea relaciones binarias de poder y represión, construyendo grupos dominantes y dominados, donde entran, precisamente, los subalternos, los monstruos y los seres abyectos, quienes son capaces de generar su propio discurso de resistencia para ampliar los márgenes constitutivos de aquello que se considera "humano". El texto de Ampuero, en suma, enfrenta al lector a la existencia de esos seres y a la violencia que estos sufren en su precaria "vida".
\end{abstract}

Palabras clave: "Subasta”, Pelea de gallos, María Fernanda Ampuero, subalternidad, monstruo.

\begin{abstract}
This article approaches the reading of the short story "Subasta" (2018) by the Ecuadorian writer María Fernanda Ampuero, from the perspective of subalternity, monstrosity and abjection. These themes are part of a prolific line in contemporary literature that seeks to question the grand discourses of power, constructed as immovable and unquestionable, around concepts such as family, gender, and childhood. The purpose is to deconstruct them to highlight their fragility, instability, and partiality. This type of literature attempts to show the vulnerability of human bodies, which are exposed to others and, therefore, to violence. The distribution of discourse itself is repressive, as it creates binary relations of power and repression, constructing dominant and dominated groups, where precisely subalterns, monsters, and abject beings appear. They generate their own discourse of resistance to expand the constitutive margins of what is considered "human". Ampuero's short story confronts the reader with the existence of these people and the violence they suffer in their precarious "life".
\end{abstract}

Key words: "Subasta", Pelea de gallos, María Fernanda Ampuero, subalternity, monster.

\footnotetext{
${ }^{1}$ Este trabajo se ha llevado a cabo dentro del marco de las investigaciones que formarán parte de las tesis doctorales de sendas autoras.

${ }^{2}$ Doctoranda en Literatura Hispanoamericana por la Universidad Autónoma de Madrid. Correo electrónico: sara.bolognesi@estudiante.uam.es. ORCID ID: 0000-0001-6121-0923.

${ }^{3}$ Doctoranda en Literatura Hispanoamericana por la Universidad Complutense de Madrid. Correo electrónico: alenbukh@ucm.es. ORCID ID: 0000-0003-4270-5546.
} 


\section{Introducción}

La presente investigación pretende analizar la imbricación de la subalternidad y la monstruosidad a través de un cuerpo femenino en "Subasta", el cuento que abre Pelea de gallos (2018), de María Fernanda Ampuero (Guayaquil, 1976), autora que se presenta como una de las voces más rompedoras y atrevidas de la literatura hispanoamericana contemporánea. Su objetivo, descubrir el lado más perverso y oscuro de la vida, explorando las relaciones íntimas que se desarrollan entre las paredes domésticas, es compartido con otras escritoras que, en los últimos años, están gozado del interés del público lector y los expertos debido a la capacidad de provocación y revulsión de sus obras. Entre ellas, cabe destacar No aceptes caramelos de extraños (2011), de la chilena Andrea Jeftanovic; Falsa liebre (2013), de la mexicana María Fernanda Melchor; La ciudad invencible (2014), de la uruguaya Fernanda Trías; Siete casas vacías (2015), de la argentina Samanta Schweblin; y Nefando (2016), de la ecuatoriana Mónica Ojeda, donde los padres, los hermanos, los hijos y la pareja, en suma, la más latente cotidianidad humana se presenta contaminada irremediablemente por las jerarquías y las violencias imperantes en la sociedad (Ovejero, 2015, s.p.). Estos textos, al presentar la familia como una entidad absorbente, agresiva y extraña, el hogar como un espacio de represión y dolor y la etapa infantil como un lastre con el cual se debe cargar por el resto de la vida, permiten revelar la brutalidad que oculta la presunta armonía del mundo global.

Las primeras publicaciones de Ampuero fueron dos antologías de crónicas, Lo que aprendí en la peluquería (2011) y Permiso de residencia (2013). Después escribió su primera colección de cuentos, Pelea de gallos, publicada por la editorial Página de Espuma, gracias a la cual fue situada en el foco de atención de la crítica. En 2021, salió a la luz su última obra, titulada Sacrificios humanos. El punto de partida de su escritura es el cuestionamiento de la figura del monstruo, un ser ficticio que, en realidad, posee características extremadamente humanas, que se esconde en los rincones más oscuros del alma y permea incluso esos espacios que deberían proporcionar seguridad, como el hogar. Así pues, afirma la escritora ecuatoriana:

La monstruosidad para mí lo es todo, toda mi literatura consiste en buscar monstruos y mostrarlos. Lo que se considera monstruo, lo que significa que nos ronden los monstruos. El dios monstruo, la madre monstrua, el amor monstruo. Un monstruo advierte, muestra, un monstruo redime a los que no sienten que lo son, un monstruo es el "otros", el monstruo es el síntoma de la sociedad. (Ampuero, 2021, s.p.)

Por ello, la figura del monstruo-humano aparece en los trece relatos que componen Pelea de gallos, puesto que la autora hilvana situaciones cotidianas distintas, pero acomunadas por la violencia y el trauma, donde los infantes y las mujeres son víctimas del abuso físico y/o psicológico de uno o más miembros de su propia familia. La institución familiar, por tanto, se configura como un lugar que no solo ha de educar a la descendencia y transmitirle valores y costumbres, sino que además la destruye mediante el espanto y la crueldad. Los niños se muestran presas fáciles para todo agresor y manipulador, razón por la cual se ven obligados a perder su inocencia antes de tiempo, para devenir adultos y enfrentarse a estos mismos en una competición protagonizada por el lema mors tua, vita mea, mientras que las mujeres deben apartar el miedo para sobrevivir a los maltratos de sus padres, hermanos y maridos. De acuerdo con Miguel Ángel Galindo Núñez, el paso de la infancia a la adultez está marcado por ritos iniciáticos forzados que provocan "una madurez repentina, violenta y que llega junto a desgracias o momentos horribles" (2021, p. 335), de modo que interrumpen el desarrollo natural de los personajes femeninos creados por Ampuero, 
los cuales tienen que convertirse en "una versión monstruosa de lo que fueron como niñas" (2021, p. 337).

Por consiguiente, María Fernanda Ampuero logra entrar en el espacio privado de cada familia, descifrar los códigos secretos que comparten padres e hijos, destapar la maldad que caracteriza inexorablemente el alma humana y escuchar tanto los ruidos como los silencios que se encierran en una casa, con el propósito de denunciar las atrocidades que se llevan a cabo dentro de las cuatro paredes domésticas y que todos - excepto los miembros que viven bajo el mismo techo- desconocen. Sin embargo, en Pelea de gallos no solo se narran las violencias del microcosmos familiar, sino también otras agresiones que se encuentran ligadas a construcciones sociales como el género, la etnia, el empleo y la condición socioeconómica, características que configuran la diferencia entre el dominado y el dominante y, más precisamente, la pertenencia a un grupo marginado.

Las dinámicas enumeradas se abordarán, a lo largo de estas páginas, recurriendo a las teorías en torno a la subalternidad propuestas por Ranajit Guha (2011) y Gayatri Chakravorty Spivak (2003), con el propósito de especificar las características de un individuo que queda definido por el discurso hegemónico como "inferior", por lo que es relegado al margen de la sociedad. De acuerdo con la pensadora india, dicha inferioridad se puede relacionar con la condición en la que vive la mujer, quien se ve silenciada y condenada a la esfera privada, idea que también se halla dentro de los estudios de algunas feministas contemporáneas, como Simone de Beauvoir y Hélène Cixous. Por su parte, Marie-Hélène Huet establece un vínculo entre el sujeto femenino y el monstruo, puesto que comparten la "disimilaridad" ante el varón, el cual representa lo normativo y lo perfecto. Por último, se definirá al monstruo a partir de las hipótesis de Jeffrey Jerome Cohen, Antonio Negri, Gabriel Giorgi y Fermín Rodríguez, ente que se muestra como "abyecto", lo que, en términos de Julia Kristeva, es tanto rehuido como deseado. En definitiva, la configuración de un personaje subalterno, femenino y monstruoso produce una vida que, según Judith Butler, carece de valor. Así pues, la elección del cuento "Subasta" se debe a que, efectivamente, en su protagonista se manifiestan todas las problemáticas apuntadas y esta investigación pretende desentrañar cómo estas se articulan en un cuerpo, con el fin de abrirle un camino contrahegemónico para la salvación y la vida, mediante lo terrorífico y lo repugnante.

Sin lugar a duda, "Subasta" se constituye como uno de los relatos más impactantes e interesantes de la antología seleccionada, puesto que la historia que narra se configura como un caleidoscopio de subalternidad. El sexo femenino de la protagonista, su desfavorable estatus socioeconómico, el ambiente en el que crece, marcado por la violencia y la pobreza, el descubrimiento temprano de la muerte, los traumas prematuros generados por el abuso sexual y la falta de una figura paterna prototípica se articulan como los componentes fundamentales de un marco infantil subalterno, en el que la monstruosidad y el horror son bienvenidos. Mientras es tan solo una niña, la muchacha sufre los abusos sexuales de los amigos de su padre, a cambio de una moneda o de un caramelo; además, está obligada a trabajar en la gallera, limpiando las heces y los cadáveres de los gallos. Por si fuera poco, para evitar las violaciones, se impregna las manos de sangre y desechos y coloca cabezas de aves muertas bajo su falda. Esta misma violencia y perversión de niñez se repiten cuando, siendo ya una joven adulta, la protagonista es secuestrada y torturada por un grupo de delincuentes, quienes pretenden venderla, lo que la convierte, una vez más, en víctima de abusos, remarcando su condición de mujer subalterna. De esta manera, "Subasta" se presenta como un pistoletazo de salida que esboza algunos de los temas principales que alimentarán Pelea de gallos: la subalternidad, la monstruosidad, la violencia machista y familiar, etcétera.

Ante todo, es necesario apuntar que el término subalterno surge en los años setenta, cuando un grupo de intelectuales sudasianistas comenzaron a cuestionar la historiografía - elitista, humanista, intelectual y de izquierdas - redactada en los países de Occidente y a proponer una distinción de la Historia escrita "desde arriba" y "desde abajo". Los estudiosos se plantearon la 
problemática de que las experiencias de los marginados, paradójicamente, son contadas por los mismos sujetos y con el mismo lenguaje que la historia del Estado, contra el cual, precisamente, se resisten y rebelan. Así pues, concluyen que no basta con buscar nuevas fuentes históricas para mostrar una subjetividad desconocida, sino que "la historia de los sectores subalternos debe ir acompañada de narrativas que se correspondan con su potencia política" (Rodríguez Freire, 2011, p. 14). En este contexto de necesidad, la literatura emerge como una vía para acoger los discursos de las minorías, porque permite dar voz a los que no pueden disfrutar de ella en la esfera pública; por ende, se abre como una exploración del "otro", el "yo", los miedos, los deseos y las inquietudes más profundas. El lenguaje literario, en suma, deviene resistencia para los cuerpos desechados por el discurso hegemónico del poder.

Ranajit Guha, uno de los fundadores de la revista Estudios Subalternos, explica que la subalternidad se encuentra en una dimensión tanto interna como externa al poder, coincidiendo así con la explicación de Jacques Derrida, quien señala que el "afuera" se configura desde el "adentro" (1998, p. 44); es decir, los límites de la exterioridad son establecidos por las relaciones de poder. La vida se organiza a través de una estructura de dobles: el "afuera" y el "adentro" se conectan mediante vasos comunicantes imposibles de romper, por lo que pueden producirse violencias arquetípicas por la incursión del afuera en el adentro y viceversa, pues se establece una suerte de simbiosis en la que un colectivo necesita del otro para existir: "El sentido del afuera siempre estuvo en el adentro, prisionero fuera del afuera, y recíprocamente" (Derrida, 1998, p. 47). Por otra parte, de acuerdo con Gyan Prakash, la subalternidad deviene una simple "apariencia", una mera construcción impuesta por el discurso dominante, una otredad no "inviolable desde el exterior, sino desde dentro del funcionamiento del poder, forzando contradicciones y dislocaciones en el discurso dominante" (apud Rodríguez Freire, 2011, p. 24). Por ello, el individuo subalterno se presenta como una vía contrahegemónica, cuyo objetivo debe consistir en eludir el discurso dominante, defensor de una realidad parcial, incompleta y distorsionada, para ampliar los márgenes de esta, aunque cualquier deslocalización cause una inestabilidad y una crisis en el sistema.

Dentro de un sistema de dominación, que impone qué se considera normativo con respecto al género, la clase, la casta y la etnia, el subalterno se define porque pertenece a un "rango inferior" (Guha, 2011, p. 69), condición desde donde está imposibilitado de ascender (Chakravorty Spivak, 2011, p. 359). Siendo así, los individuos que conforman los grupos marginados no tienen voz, el poder no los tiene en cuenta, ni siquiera para ejercer sobre ellos la opresión de la sujeción, es decir, sus vidas no importan, puesto que ni siquiera se toman en cuenta dentro de la categoría de "lo humano" (Butler, 2010, p. 55). Además, según el discurso dominante, pertenecen a una "minoría", la cual, sin embargo, lo es solo desde el punto de vista terminológico, ya que empíricamente una gran parte de la humanidad pertenece a una categoría subalterna. Las mujeres se sitúan precisamente en el espacio de esa minoría innombrable y desechada, de acuerdo con Spivak, porque lo "femenino", en la tradición falocéntrica, no puede ser representado, ya que la mujer es un ser otro indeterminado (2003, p. 327).

Por ende, la relación de la subalternidad con el feminismo se sustenta sobre el carácter foráneo del sexo femenino respecto a la comunidad: la mujer se incorpora a la subalternidad no por su manera de actuar, sino a causa de su sufrimiento de las acciones de otros (Chakravorty Spivak, 2011, p. 358). En conclusión,

Dentro del itinerario suprimido del sujeto subalterno, la pista de la diferencia sexual está doblemente suprimida. [...] Si en el contexto de la producción colonial el subalterno no tiene historia y no puede hablar, el subalterno como femenino está aún más profundamente en tinieblas. (Chakravorty Spivak, 2003, p. 328) 
En esta misma línea, las teorías de Simone de Beauvoir proponen que el punto de partida de sus estudios en torno al lugar que ocupa la mujer dentro de la sociedad coincide con una amarga, pero inamovible consciencia: la falta de simetría entre el hombre y la mujer. Abarcando los discursos que han construido, deconstruido y reconstruido lo femenino, llega a la conclusión de que este desequilibrio se debe a que, desde los orígenes del ser humano, solamente las mujeres se han visto obligadas a definirse por su sexo, mientras que un varón "nunca empieza considerándose un individuo de un sexo determinado: se da por hecho que es un hombre" (1981, p. 35). En definitiva, la mujer se constituye a través de su "carencia" frente al sujeto masculino, quien simboliza lo normativo, lo perfecto y lo humano, motivo por el cual es identificada con "el otro".

Hélène Cixous explica que el pensamiento se organiza por oposiciones binarias, es decir, si el hombre representa la parte perfecta, activa y dominante del binomio, la mujer será su antónimo, esto es, defectuosa, pasiva y sumisa; por ende, se encuentra excluida de la escena social donde se libra la Historia. Ella está destinada a ser, pues, la mitad no-social, no-política, nohumana de la estructura viviente, siempre la facción naturaleza/cuerpo, en relación inmediata con sus apetitos y sus afectos (1995, p. 18). El cuerpo femenino, al carecer de los atributos varoniles, se considera imperfecto y defectuoso, así que se repiensa como una mera máquina sexual, interesada exclusivamente en la reproducción (Beauvoir, 1981, p. 48). Y es esta conexión con los impulsos más íntimos lo que produce un acercamiento de la mujer a lo animal y, por consiguiente, al monstruo. De acuerdo con Gabriel Giorgi y Fermín Rodríguez, el monstruo es aquel ser en cuyo cuerpo no es posible distinguir lo humano de lo animal, es decir, se trata de un ente que asume su parte salvaje y pulsional en lugar de huirla y resistirla, porque su vida emerge como "lo monstruoso, lo animalizado, lo impersonal, lo inhumano" (Giorgi y Rodríguez, 2007, p. 11), como una fuerza que atraviesa las construcciones normativas, capaz de amenazarlas con su propia potencia de devenir y alteración.

Otro aspecto que el monstruo comparte con las mujeres es su carácter de ser antinatural, según Jeffrey Jerome Cohen (1996), porque personifica espacios distintos y distantes y representa la diferencia cultural, política, racial, económica y sexual (p. 7). Así pues, al no ajustarse a las características de una hegemonía consolidada, deviene el precursor de una crisis (p. 6). El individuo monstruoso no solo perturba y se resiste a un orden, sino que también amenaza con romperlo, incorporando así el miedo y la angustia a la imaginación de una determinada cultura, configurándose como una proyección y construcción del propio ser humano (Cohen, 1996, p. 4) y, una vez más, convirtiéndose en el tan temido "otro". Y es la amenaza de crear un devenir alternativo lo que causa un profundo terror en el sistema, ya que el monstruo y el subalterno poseen una potencia para desarticular sus márgenes y para crear nuevas formas de vida, que difieran de la normatividad, por lo que Antonio Negri (2007) afirma que "si hay monstruo el resto se transforma y se desestabiliza" (p. 106). Si la mujer se caracteriza por la carencia, el monstruo se configura como una oposición contra las pretensiones de la norma, es más, "el monstruo ha devenido biopolítico" ( p. 116), porque el poder posee sus propias capacidades para crearlo, no solo mediante la mitificación, sino también a través de la ingeniería genética, definida por el italiano como la posibilidad de crear cuerpos que pueden ser modificados o corregidos de acuerdo a la necesidad: "O, más aún, pedazos de cuerpos que pueden servir para modificar otros cuerpos, a veces para corregir los defectos genéticos o patológicos, otras veces para aportar correcciones a la naturaleza" (p. 126).

Sin embargo, Marie-Hélène Huet afirma que, de acuerdo con las teorías aristotélicas, la monstruosidad no se encuentra vinculada principalmente a las imperfecciones físicas, sino a una deficiencia en el desarrollo del vínculo paternofilial, caracterizada por una apariencia fallida entre el infante y sus progenitores, la cual conlleva un vacío genealógico abismal e irresoluble. En lugar de reproducir la figura del padre, conforme a las rigurosas leyes naturales, la cría monstruosa presenta cierto parecido con otra especie, de manera que deviene un sujeto extraño, no identificable con sus criadores (Huet, 1993, p. 4). El ser que juega un rol fundamental en esta falta de semejanza 
es la madre, cuyos deseos violentos y el agudo dolor que experimenta durante el embarazo y/o el parto se materializan en su niño, es decir, en este confluyen los caprichos, la ira y el sufrimiento materno (Huet, 1993, p. 1). Por consiguiente, la simbolización de lo monstruoso y la conceptualización de lo femenino se configuran como dos caras de la misma moneda, "the monster and the woman thus find themselves on the same side, the side of dissimilarity" (Huet, 1993, p. 3. Cursiva en el original); la monstruosidad no solo queda representada por la disimilaridad entre los padres y el sujeto monstruoso, sino también por la figura materna que lo ha engendrado.

En suma, tras el recorrido teórico que se ha llevado a cabo es posible afirmar que los conceptos de subalternidad y monstruosidad manejados en esta investigación y puestos en relación con la feminidad comparten un claro vínculo que los une y los relega a una posición de inferioridad, marginalidad y silencio. Dicha relación reside en su potencia política de alteración y dislocación de las normas impuestas por la hegemonía y el miedo que esta fuerza genera en el propio poder. Ante la amenaza que suponen los no-sujetos, el discurso se ve obligado a mitificarlos, es decir, a convertirlos en la pesadilla y el demonio que debe ser extirpado de la sociedad y silenciado, cuando no aniquilado. Pero la liquidación total de las quimeras es imposible, porque se encuentran inmersas dentro del propio mecanismo del sistema dado que el "afuera" está preso en el "adentro", el monstruo en la norma, el subalterno en la clase dominante y las mujeres en el centro propio de la vida. Por todo esto, la caracterización de la protagonista de "Subasta", desde el comienzo, se presenta como subalterna y monstruosa: ella es una joven, de nacionalidad hispanoamericana, que carece de suficientes recursos económicos para llevar una existencia "digna". "Claramente, si usted es pobre, negra y mujer está metida en el problema en tres formas" (2003, p. 338) escribe la filósofa india Gayatri Chakravorty Spivak al tratar el conflicto de la subalternidad.

También resulta significativo el hecho de que, a lo largo del texto, en ningún momento quede especificado el nombre de la muchacha, así como cualquier otro elemento que pueda identificarla, como la edad o el lugar de procedencia. De esta manera, su anonimato simboliza su falta de importancia dentro de la sociedad, aunque, por otra parte, la voz narradora deviene la de todas aquellas mujeres que han sido silenciadas y olvidadas por el sistema patriarcal, es decir, sus palabras se hacen universales. Tan solo es posible reconocer algunas referencias a la ciudad ecuatoriana de Guayaquil, como la mención de la carretera donde se abandona a la protagonista tras el fracaso de la subasta, la Vía Perimetral, que rodea toda la ciudad y se identifica como un sitio donde los homicidas dejan los cadáveres de sus víctimas. Otro de los secuestrados vive en una urbanización llamada "Vistas del Río", cuyo referente real quizás sea la urbanización privada Vista al Río que, efectivamente, se halla en esta misma localidad. Sin embargo, estas indicaciones son nimias, por lo que no pretenden situar la narración en un lugar concreto, sino que convierten el relato en una historia que puede ocurrir en cualquier espacio geográfico.

El presente narrativo del cuento se desarrolla en un ambiente desconocido, un garaje, donde la protagonista se encuentra secuestrada junto con otras víctimas que están puestas a la venta en una subasta. Sin embargo, el olor a gallos que impregna el ambiente la remanda a las experiencias vividas durante su infancia cuando su padre, gallero, como no tenía con quien dejarla, la llevaba consigo a las peleas. Así pues, la narradora se detiene en una larga regresión, en la que no solo cuenta sus primeros contactos con la violencia y la muerte y, por consiguiente, su temprana pérdida de la inocencia, sino también la relación con su padre:

Las primeras veces lloraba al ver al gallito desbaratado sobre la arena y él se reía y me decía mujercita. Por la noche, gallos gigantes, vampiros, devoraban mis tripas, gritaba y él venía a mi cama y me volvía a decir mujercita. (Ampuero, 2018, p. 11. Cursiva en el original)

El vocativo que emplea el progenitor para dirigirse a su hija, "mujercita", se convierte en una especie de insulto, un sinónimo de "débil" que produce rechazo en la protagonista, quien, poco 
a poco, se va insensibilizando ante la violencia que la circunda. Dicho término despierta toda una serie de imágenes estereotipadas por las cuales una niña tiene que ser sumisa, frágil y dócil, características que la joven de "Subasta" se ve obligada a abandonar antes del tiempo, para poder sobrellevar el horror al que se enfrenta cada día. En efecto, la chica no solo debe asistir a las peleas de gallos y retirar sus cadáveres, sino que, además, tiene que lidiar con los abusos de los amigos de su padre, quienes, a cambio del acto sexual, le entregan una moneda o un caramelo: "De camino, siempre algún señor gallero me daba un caramelo o una moneda por tocarme o besarme o tocarlo y besarlo. Tenía miedo de que, si se lo decía a papá, volviera a llamarme mujercita" (Ampuero, 2018, p. 11. Cursiva en el original). Por lo que, desde las primeras páginas del relato, se introduce un mecanismo de exclusión social relacionado con el sexo biológico del individuo y su edad, o sea, la protagonista de "Subasta" deviene subalterna por su condición de niña.

El cuerpo de la protagonista, por lo tanto, es percibido como un instrumento de placer por el grupo dominante, constituido por los amigos del padre y por él mismo, de forma que se hace "invisible en calidad de humano" (Cixous, 1995, p. 24), porque se convierte en una mera herramienta: para unos, un juguete sexual y, para otro, tan solo una "mujercita", que no puede realizar otra tarea que no sea recoger basura y limpiar. Y esta invisibilidad aumenta si se tiene en cuenta que dicho cuerpo no solo es femenino, sino también pueril: en esta circunstancia, entonces, la narradora se encuentra sometida a una doble condición de subalternidad, puesto que es una mujer y, al mismo tiempo, aún es una niña. Si la figura femenina, como ya se ha señalado, está excluida de toda vida pública (Cixous, 1995, p. 18), por su parte, los infantes también pueden considerarse como seres discriminados, pues su mirada ingenua, imprecisa e incompleta no es tomada en cuenta por las autoridades, así que tampoco tienen la oportunidad de incluirse en el poder político y económico (Jeftanovic, 2011, p. 28).

Ante los abusos sexuales de los galleros y la inactividad del padre, la protagonista se ve obligada a protegerse por su cuenta, sacando provecho de la inmundicia que la rodea. Así pues, para evitar que se acerquen a ella, se cubre las manos, las rodillas y la cara con una mezcla hecha con "la caca y la sangre y las vísceras", porque resulta que da asco a "esos señores tan machos" (Ampuero, 2018, p. 12). Además, con el fin de que no le levanten la falda y la violen por la noche, antes de dormirse esconde "la cabeza de un gallo en medio de las piernas. Una o muchas. Un cinturón de cabezas de gallitos. Levantar una falda y encontrarse cabecitas arrancadas tampoco gustaba a los machos" (Ampuero, 2018, p. 12). Estos actos representan el principio de la transformación de la "mujercita" en un ser abyecto, quien, finalmente, resulta repugnante para aquellos que ejercen la violencia sobre ella. De esta manera, la niña subvierte su caracterización infantil de "presa fácil", cambio que los propios agresores advierten rápidamente. Entre burlas y quejas, en efecto, estos le señalan al padre que su "hija es una monstrua" (Ampuero, 2018, p. 12), afirmación que el progenitor se toma a risa, mientras sigue emborrachándose y brindando con ellos.

Tras los abusos sufridos, la ingenuidad de la niña comienza a diluirse y, conforme avanza el texto, se convierte en una joven mujer, astuta y resolutiva, dispuesta a abrazar la suciedad y la muerte para sobrevivir. Por lo tanto, dentro del imaginario machista, la protagonista se hace monstruosa y abyecta, esto es, se erige en contraposición con una identidad normativa, la cual, en este caso, coincidiría con una muchacha que sufre pasivamente los abusos. De acuerdo con la filósofa búlgara Julia Kristeva (2006), "lo abyecto" se configura como una frontera, se sitúa en los márgenes de la norma excluyente, de modo que no tiene otra cualidad que la de oponerse al "yo" (pp. 8-11). Es decir, la niña, y después la joven, se sirve de lo repugnante para generar resistencia y tratar de sobrevivir dentro de este contexto de violencia. En la misma línea, Judith Butler (2002) defiende que lo abyecto representa un "espectro amenazador para el sujeto" (p. 20), puesto que se constituye a través de su exclusión de la esfera normativa. Es decir, en el momento en que la niña impregna su cuerpo de inmundicia y se rodea de las cabezas cortadas de los gallos muertos manera en la que asume su abyección — adquiere otra categoría que se aleja completamente de la 
que le corresponde culturalmente por su sexo y edad, razón por la cual el grupo dominante masculino la rechaza y excluye. En definitiva, la abyección, al igual que la subalternidad, reside en esas zonas inhabitables de la vida social y se fundamenta según lo que el poder etiqueta como "exterior", "excluido" y "distinto", así que ambos conceptos solo pueden concebirse en relación con el discurso normativo, en sus márgenes y formando sus propios límites (Butler, 2002, p. 27).

Retomando la figura del padre, ciertamente el de "Subasta" no es un progenitor modélico porque no le proporciona ni protección ni cariño a su hija. Según el imaginario tradicional, este debería desempeñar el rol de protector, maestro y tutor para sus crías y representar la autoridad y el ideal viril dentro del núcleo familiar (Lacan, 2003, pp. 83-84); en cambio, en el cuento de María Fernanda Ampuero, el progenitor se presenta como un hombre borracho, que obliga a la niña a trabajar en la gallera recogiendo los cuerpos de las aves y autoriza los abusos ejercidos por sus amigos sobre la joven. No obstante, el padre sí presenta algunos gestos de compasión hacia su prole: por ejemplo, por la noche, mientras la niña está durmiendo, es él quien se encarga de tirar los cadáveres de los gallos y aguanta las burlas de sus compañeros, los cuales lo llaman "maricón" (Ampuero, 2018, p. 12) y le preguntan que para qué tiene a una hija si es él quien lleva a cabo las tareas domésticas. A todos los traumas citados, cabe añadir que la narradora no cuenta con una figura materna, porque nunca menciona a nadie ni siquiera parecido a una madre, de manera que, de acuerdo con Sarah Thomas, su existencia se configura como la de un sujeto que no puede formar parte de la sociedad de una manera fácil o normativa (apud Jeftanovic y Pérez, 2011, p. 88).

Si bien el flashback hacia la época infantil subraya las facetas más negativas del padre y las experiencias traumáticas que este causa en la vida de su hija, en realidad, se muestran indispensables para poder sobrevivir al secuestro que la protagonista sufre cuando es una jovenadulta: "Para mí, dentro de su ignorancia o condición de padre soltero, la única manera de salvar a su hija era diciéndole que dejara de ser lo que ella era, que se endureciera" (2019, s.p.) apunta la propia María Fernanda Ampuero. En efecto, tras el relato de su infancia, el lector descubre que la muchacha ha sido raptada por un taxista, quien la ha llevado a un lugar desconocido: "Creo que me quedé dormida un momento y, de repente, al abrir los ojos, estaba en una ciudad desconocida. Un polígono. Vacío. Oscuridad. La alerta que hace hervir el cerebro: se te acaba de joder la vida" (Ampuero, 2018, p. 14). Ahí, ella se encuentra desubicada, aunque identifica y reconoce los mismos olores que marcaron su infancia:

Sé que aquí, en algún lado, hay gallos, porque reconocería ese olor a miles de kilómetros. El olor de mi vida, el olor de mi padre. Huele a sangre, a hombre, a caca, a licor barato, a sudor agrio y a grasa industrial. No hay que ser muy inteligente para saber que este es un sitio clandestino, un lugar refundido quién sabe dónde, y que estoy muy pero que muy jodida. (Ampuero, 2018, pp. 12-13)

Dentro del garaje, la descripción de todo acontecimiento aparece fragmentada, parcial e imprecisa, debido a que la visión de la protagonista es limitada por un saco que le cubre la cabeza. De acuerdo con su imaginación, en esa misma habitación, hay un hombre gordo, cuyas características se construyen a partir del sonido de su voz. Por las palabras que este pronuncia, la muchacha se da cuenta de que no es la única víctima del secuestro:

Lo imagino gordo, calvo y sucio, con camiseta blanca sin mangas, short y chancletas plásticas, le imagino las uñas del meñique y del pulgar largas. Habla en plural. Aquí hay alguien más que yo. Aquí hay más gente de rodillas, con la cabeza gacha, cubierta por esta asquerosa tela oscura. (Ampuero, 2018, p. 13)

Esta voz sin rostro amenaza constantemente a los presos con "meterles un tiro en la cabeza" (Ampuero, 2018, p. 13), es decir, se erige como la instancia de dominación y establece un régimen 
de terror mediante la intimidación y el miedo, por lo que logra constituir una relación binaria de víctimas y victimarios. De esta forma, dentro del microcosmos del garaje, se genera una especie de panóptico, que reproduce las relaciones de represión que se dan en el exterior.

Y, efectivamente, como panóptico, también reproduce el machismo imperante en el patriarcado. En consecuencia, las mujeres se llevan la peor parte y se rodean de un silencio que hiere por sí mismo, lo que se muestra en los golpes y las amenazas de muerte por parte del gordo hacia una chica que, al no soportar el tacto de la pistola en su sien, llora desesperadamente, y se explicita en la elisión del hombre que está arrodillado a la derecha de la protagonista, quien explica que ha oído hablar de este tipo de secuestros, aunque pensaba que eran una leyenda:

Se llaman subastas. Los taxistas eligen pasajeros que creen que pueden servir para que den buena plata por ellos y para eso los secuestran. Luego los compradores vienen y pujan por sus preferidos o preferidas. Se los llevan. Se quedan con sus cosas, los obligan a robar, a abrirles sus casas, a darles sus números de tarjeta de crédito. Y a las mujeres. A las mujeres. (Ampuero, 2018, pp. 13-14)

Mientras los secuestrados se encuentran atados y aterrorizados, se escucha un rumor de gente que ríe y bebe. De repente, los presos son arrastrados al centro de la sala, donde comienza la subasta bajo la dirección del gordo, el cual parece un presentador televisivo. Para él, todo aquello no es más que un espectáculo con el cual ganar dinero y gracias al cual disfrutar del sufrimiento ajeno y la tortura de sus víctimas, ante un público compuesto por ladrones, violadores, asesinos "o algo peor" (Ampuero, 2018, p. 15). Sumergida en este ambiente de opresión y miedo, la protagonista solo puede concentrarse en los gallos y los hombres de su infancia, bajo la voz de su padre repitiendo "Ya, no seas tan mujercita, son galleros, carajo" (Ampuero, 2018, p. 16. Cursiva en el original), la frase que tanto le molestaba de pequeña y que, ahora, se ha convertido en el mantra que le da fuerzas para resistir.

El primer "participante" de este teatro del horror es Ricardo, marido y padre de dos hijos, un bebé de ocho meses y un niño de tres. Todo eso importa poco ante su urbanización privada, su cartera, sus zapatillas Adidas y su reloj de marca, pues los victimarios juzgan por su apariencia que "Ricardooooo ha de tener plaaaaaaaataaaaaaa" (Ampuero, 2018, p. 16). Ahora bien, cabe destacar que la condición acomodada de Ricardo se muestra significativa dentro del relato, porque genera cierta envidia de clase en el propio gordo, quien considera la zona de Vistas del Río, donde vive su víctima, un sitio "donde no podemos ni asomarnos los pobres" (Ampuero, 2018, p. 16). Este dato aumenta considerablemente el valor de Ricardo: de ofrecer solo ochocientos, finalmente, los secuestradores lo venden por cinco mil dólares. Así pues, Ricardo, que en el mundo exterior debía ser un personaje adinerado, con bastante poder adquisitivo y posiblemente un puesto laboral y social importante, en el microcosmos del garaje representa una víctima más, despojada de todas sus pertenencias y privada de su valor humano. En definitiva, el precio final de su vida se mide por su vivienda y su cartera, no importa si tuvo o no poder fuera, en el polígono es una mera moneda de cambio.

La siguiente rehén es una joven de "veintipocos" (Ampuero, 2018, p. 16) años, llamada Nancy, que en ningún momento ha parado de llorar, por lo que se lleva varios golpes. En este caso, no importa su dinero, sino su cuerpo, así que "el gordo la toca. Lo sé porque dice miren qué tetas, qué ricas, qué paraditas, qué pezoncitos y se sorbe la baba y esas cosas no se dicen sin tocar y, además, qué le impide tocar, quién" (Ampuero, 2018, p. 16. Cursiva en el original). Con la muchacha se despliega un episodio de lo más desagradable, en el cual el gordo se ensaña con su cuerpo violándola y agrediéndola ante todos los presentes, quienes, lejos de horrorizarse o repugnarse, aúllan como verdaderos animales y se deleitan con el espectáculo denigrante, repulsivo y aterrador: 
A Nancy el gordo la desnuda. Escuchamos que abre su cinturón y que abre los botones y que le arranca la ropa interior, aunque ella dice por favor tantas veces y con tanto miedo que todos mojamos nuestros trapos inmundos con lágrimas. Miren este culito. Ay, qué cosita. El gordo sorbe a Nancy, el ano de Nancy. Se escuchan lengüeteos. Los hombres azuzan, rugen, aplauden. Luego el embestir de carne contra carne. Y los aullidos. Los aullidos. (Ampuero, 2018, pp. 16-17)

Finalmente, la compra el "caballero del anillo de oro y el crucifijo" (Ampuero, 2018, p. 17) por tres mil quinientos dólares, es decir, mil quinientos dólares menos que Ricardo, porque "el sexo es más barato que la plata" (Ampuero, 2018, p. 17). Las joyas que identifican al comprador no son accesorios casuales: el hecho de que el caballero lleve un crucifijo implica que, posiblemente, sea un hombre religioso o, quizás, alguien que pertenece a la Iglesia, detalle que convierte este episodio en el más deplorable moralmente. Es decir, el lector intuye que ese "hombre de Dios" compra a una muchacha que ha sido violada ante sus ojos para seguir abusando de ella. Esa religiosidad concentrada en el símbolo de la cruz hace patente la perversidad existente en el seno de la propia Iglesia, ya que remite a las violaciones a jóvenes perpetradas por los religiosos en los "templos" consagrados a Dios.

El próximo secuestrado es el chico del bebé de ocho meses y el niño de tres años. Es curioso señalar en este punto que, anteriormente, Ricardo y el muchacho parecían la misma persona, confusión que tampoco es accidental, sino que se debe a que la voz narrativa no es omnisciente. En efecto, la visión de la protagonista se ve limitada, como ya se ha especificado, por el saco que lleva en la cabeza, lo cual hace que ella confunda las voces y crea que Ricardo y el joven son la misma persona, por lo que esta parte del relato se fundamenta en las suposiciones de la narradora, cuyo testimonio se hace poco fiable. A través de golpes y torturas, el gordo le ha sonsacado a su penúltima víctima toda la información y resulta que es "un pez gordísimo para la subasta: plata en diferentes cuentas, alto ejecutivo, hijo de un empresario, obras de arte, hijos, mujer" (Ampuero, 2018, p. 17). La narradora, una vez más, supone que los competidores de la subasta lo adquirirán para, posteriormente, pedir rescate, así ganarán aún más dinero. El chico es la víctima más cara: es comprado por veinte mil dólares, por un hombre al cual nadie se atreve a responder - ni siquiera el gordo, quien ha llevado el show hasta ahora, hace comentarios-, hecho que muestra que, dentro de la propia subasta, existen jerarquías inalterables, en las que esta voz aterradora parece ser la persona más peligrosa.

La última de las víctimas en ser subastada es la narradora. Cuando llega su turno, solamente piensa en los gallos y las estrategias que le servían de pequeña para resistir los abusos de los amigos de su padre; recuerda que la inmundicia, la sangre y las heces repugnan a los hombres, por lo que decide "abrir sus esfínteres", moviéndose como si estuviera poseída y pronunciando frases incomprensibles:

Me baño las piernas, los pies, el suelo. Estoy en el centro de una sala, rodeada por delincuentes, exhibida ante ellos como una res y como una res vacío mi vientre. Como puedo, froto una pierna contra la otra, adopto la posición de una muñeca destripada. Grito como una loca. Agito la cabeza, mascullo obscenidades, palabras inventadas, las cosas que les decía a los gallos del cielo con maíz y gusanos infinitos. Sé que el gordo está a punto de dispararme. (Ampuero, 2018, pp. 17-18)

Al vaciar su vientre ante los delincuentes de la sala, la protagonista deviene una opción de oposición ante la norma, una alternativa para escapar de las pretensiones del poder (Negri, 2007, p. 107). Este gesto de resistencia o, mejor, de supervivencia, la convierte en un monstruo, es decir, en un individuo que se rebela a la hegemonía y, por tanto, representa un peligro para la estabilidad de esta. Al contrario de lo que ella supone, el gordo no dispara, pero sí la golpea en la cara, por lo 
que la muchacha llega a morderse la lengua y se colma de sangre, la cual se mezcla "con la mierda y la orina" (Ampuero, 2018, p. 18).

Ante este espectáculo abyecto y repugnante, la narradora da rienda suelta a una risa histérica que implica el culmen de su transformación en un ser monstruoso, lo que deja a todos los presentes atónitos: "El gordo no sabe qué hacer. / ¿¿Cuánto dan por este monstruo? / Nadie quiere dar nada" (Ampuero, 2018, p. 18). De acuerdo con Negri, todo monstruo debe ser extirpado y expulsado del orden social, pero su exclusión resulta imposible dado que se encuentra muy incluido dentro del propio sistema, así que es necesario tratar de normalizarlo y someterlo a un control y una vigilancia constantes (2007, p. 107). La aparente indiferencia del gordo ante tal imprevisto y su tentativo por romper la tensión y avanzar en la subasta se configuran precisamente como un intento de normalizar al "monstruo", con el propósito último de que uno de los presentes se anime a comprarlo. No obstante, el monstruo no solo se configura como un ser indomable, que está al margen, sino también como un individuo que es repudiado por el orden hegemónico, de modo que, aunque el jefe de la subasta solamente pide quince o veinte dólares por ella, nadie puja, ni siquiera por su reloj, cartera y teléfono. Finalmente, puesto que la protagonista no representa ningún "bien" que pueda subastarse, es limpiada con una manguera de coches y abandonada por los secuestradores en la Vía Perimetral.

La protagonista no hace más que intentar sobrevivir a través del único medio que posee en el momento de la subasta, su propio cuerpo. Un cuerpo que deviene abyecto y repugnante por su animalización más absoluta, que resulta grotesca para el público de delincuentes, lo que implica una alteración de su esquema de inteligibilidad y, por tanto, la convierte en un ente infrahumano, confirmando, una vez más, su similitud con el monstruo. De esta forma, mientras a los hombres del relato les repugnan la sangre y las heces, la protagonista crea un refugio entre la inmundicia, porque su vida emerge como "lo monstruoso, lo animalizado, lo impersonal, lo inhumano" (Giorgi y Rodríguez, 2007, p. 11). De la misma manera que el monstruo, por adoptar formas distintas de las reales, simboliza un desorden dentro de un sistema que pretende normalizar a los individuos"The monster is thus the very definition of imposture [...]. The monster assumes the appearance of that which is not" (Huet, 1993, p. 35. Cursiva en el original)_, la protagonista de "Subasta" se convierte en una metáfora de la desviación de la hegemonía y la ética por asumir una identidad ficticia.

Por consiguiente, el comportamiento abyecto que abraza la joven no le pertenece por naturaleza, sino que es el fruto de una estrategia que pretende salvarle la vida, desarrollada dentro de un contexto específico y bajo un fin concreto. En otras palabras, su forma de ser depende de las condiciones e instituciones en las que está inserta, porque estas delimitan su capacidad para lidiar con el entorno hostil. Esta facultad incluye una amplia gama de sentimientos, como el placer, la rabia, el sufrimiento o la esperanza (Butler, 2006, pp. 57-58) y, en el caso de la protagonista de "Subasta", esta respuesta es la recurrencia a los elementos más repugnantes que la rodean, con los cuales impregna su cuerpo, para generar una reacción de rechazo en sus abusadores y secuestradores. Así pues, la interpretación de una respuesta afectiva surge como consecuencia de un campo de inteligibilidad, es decir, los amigos del padre y el público de la subasta interpretan la conducta de la muchacha como un acto monstruoso; sin embargo, para ella - y para el lector - su comportamiento está completamente justificado por el contexto en el que se encuentra. En definitiva, los seres humanos desarrollan respuestas morales y corporales como reacciones a cuestiones de supervivencia (Butler, 2010, p. 71).

La manera en la que los demás interpretan a la protagonista la denigra a una condición precaria y subalterna: se encuentra animalizada y, en suma, convertida en monstruo, así su valor se reduce a la nada. Cixous explica que el dominio del hombre reside en lo propio, lo normativo y lo dominante, mientras que el terreno de la mujer es marginal y nómada pues en ella habita lo salvaje, la parte sombría de lo doméstico (1995, p. 53). Por ello, el valor de los varones es superior al de Nancy y, con creces, al de la narradora, puesto que el de los primeros coincide con sus 
pertenencias económicas y el de las muchachas con sus cuerpos que, tal y como explicita el propio texto, tienen un precio inferior. Asimismo, Judith Butler (2010) expone que el valor de una vida se calcula por su capacidad de ser llorada (p. 32), de manera que el precio de la existencia de los dos hombres resulta ser más elevado que el de la protagonista, porque tienen a familiares que les extrañarían. En particular, la vida del muchacho joven cobra mucha importancia por tener a un padre empresario, una mujer y dos hijos, razón por la cual los secuestradores pretenden pedir rescate por él. Aunque se pasa por alto el entorno de Nancy, el lector sí conoce el de la otra rehén, es decir, sabe que la narradora no debe tener a nadie quien vaya a llorar su muerte, salvo ella misma, y efectivamente ante la carencia de valor en su vida, se arriesga a escapar, aun ante la amenaza de ser asesinada.

Todas las víctimas suman un precio de veintiocho mil quinientos dólares, es decir, las vidas de tres personas corresponden a un valor económico bastante irrelevante y una de ellas ni siquiera se merece la más miserable cifra de dinero. Asimismo, cabe destacar que el peligro que corren los delincuentes al secuestrar y vender a las víctimas es alto considerando que se arriesgan a ser arrestados; no obstante, no solo se concluye que su situación socioeconómica es precaria, por lo que no les queda otra opción que realizar este tipo de delitos, sino también que la protección policial de la zona debe ser deficiente. Por consiguiente, la falta de un sistema de seguridad sólido deja el camino abierto a toda una serie de actos criminales que, posiblemente, jamás serán ajusticiados. Así pues, todas las vidas resultan precarias en un contexto donde la violencia se produce aleatoriamente, esto es, el secuestrador se convierte en sujeto dominante, a pesar de su clase social, etnia, poder adquisitivo, etcétera, y las víctimas, en concreto, los dos hombres, que pertenecen a estratos sociales elevados, se vuelven igualmente subalternos frente al gordo armado, ya que sus cuerpos son susceptibles de sufrir violencia. Esta clase de situaciones muestra que toda vida puede ser violentada, porque las relaciones humanas exponen inexorablemente los cuerpos a los otros (Butler, 2006, p. 46).

\section{Conclusiones}

A modo de conclusión, la voz de la protagonista de "Subasta" se presenta como un estallido arrasador, que cuestiona los discursos dominantes y opresores, derrumba la Ley establecida $a$ priori y explora las violencias y las injusticias que la Historia prohíbe contar, con el fin de restituir la importancia que les corresponde a los seres excluidos por la sociedad. La literatura, por lo tanto, deviene la cuna de esta mirada subalterna y monstruosa: los reprimidos sobreviven en la poesía, defiende Hélène Cixous, porque las palabras sacan fuerza del inconsciente, y es precisamente en él donde habitan los seres marginados (1995, p. 63). En la misma línea, Giorgi y Rodríguez (2007) afirman que la literatura es el espacio habitado por el monstruo, cuya vida, como potencia de alteración, pasa por el lenguaje, pero lo desborda y choca con su límite, el cual coincide con el lugar de la literatura. En esta frontera, las palabras se deshacen de sus significados compartidos y de su poder normalizador para articularse a través de aquellos cuerpos que marcan una vía de mutación, una vuelta monstruosa e informe, en suma, una trayectoria anómala (p. 26). En este sentido, el relato que inicia Pelea de gallos sugiere que, ante la imposición del discurso dominante, existe la posibilidad de crear otro que genere una transformación a través del arte y la escritura, donde se abre un camino alternativo para la comprensión del mundo, mediante "lo diverso". Ahí se erige un "yo" hasta entonces desconocido, que impulsa la exploración del "otro", de los individuos sin voz que tratan de crear su propio lenguaje, de manera que emergen "nuestras mujeres, nuestros monstruos, nuestros chacales, nuestros árabes, nuestros semejantes, nuestros miedos" (Cixous, 1995, p. 43).

Así pues, la narradora de "Subasta" se hace claramente cargo de hablar en nombre de dos categorías subalternas, la mujer y el infante, adoptando una perspectiva que busca hacer visibles las tensiones entre los dominantes y los dominados y, en última instancia, pretende imponer una 
resistencia ante las ideologías hegemónicas, mediante un lenguaje corporal de lo abyecto y lo monstruoso. Al igual que la escritura femenina, no procede "desde arriba" (Cixous, 1995, p. 53), puesto que la mujer se encuentra en un estado de inferioridad con respecto al hombre, la mirada del niño se genera "desde abajo", no solo por su tamaño corporal, sino también por su ignorancia ante múltiples saberes (Jeftanovic, 2011, p. 28). Por este motivo, la niña de "Subasta", antes del tiempo, se ve obligada a abandonar la perspectiva inocente - $-\mathrm{y}$, por tanto, desventajada - que caracteriza a todo infante; es decir, desde tierna edad debe aprender a analizar con minucia las situaciones y buscar una solución al peligro como una adulta. De esta manera, desde su posición subalterna, la protagonista no se convierte en un individuo pasivo, que aguanta las injusticias sin oponerse a ellas, sino que actúa como un sujeto activo, suficientemente valiente para lidiar con los traumas, capaz de desarrollar mecanismos de defensa ante la violencia y dispuesto a devenir un monstruo para sobrevivir.

En suma, con esta investigación se han pretendido rastrear las estrategias que asume un individuo subalterno a través de un cuerpo femenino y monstruoso, para ejercer una resistencia ante la opresión y la violencia. La protagonista sin nombre de "Subasta" se erige como un ente repugnante e inhumano a los ojos de los hombres, quienes, sin reparos, abusaban de ella cuando era una niña y pretenden hacer lo mismo vendiéndola, como ganado, siendo una joven adulta. Ella, sin embargo, en lugar de asumir su exigido destino de sumisión, se resiste aceptando su lado perverso, salvaje y animal y borrando los límites entre su cuerpo y el entorno de inmundicia en el cual se desarrolla su historia, bien sea mediante las heces y la sangre de los gallos, bien sea mediante sus propias heces, orina y sangre. De esta manera, en el cuerpo de la protagonista convergen las categorías de subalternidad - por su condición presuntamente subordinada que se desprende de su clase social, género y etnia - con la monstruosidad, ya que deviene un ser alternativo, que amenaza las estructuras de lo normativo.

Este artículo se inserta en una línea prolífica de investigación literaria contemporánea que indaga en los mecanismos textuales que permiten rebasar los límites del cuerpo considerado humano, del lenguaje y lo inteligible, de lo narrable, a través del horror, lo grotesco, la violencia y la monstruosidad que se esconden en lo más íntimo y cotidiano de la vida, es decir, en la familia, el hogar y la infancia. Un mundo silenciado y silencioso, hasta ahora, momento en el cual muchos autores y, en particular, autoras se atreven a indagar en dichos espacios, con el fin de evidenciar la parte más perversa de lo humano. De esta forma, el estudio llevado a cabo en estas páginas representa una aportación mínima que ilumina tan solo una parte del universo literario que se abre en la narrativa hispanoamericana contemporánea, donde numerosos escritores, como la propia María Fernanda Ampuero, están creando textos que no buscan una lectura cómoda y hedonista, sino que pretenden remover la consciencia de los lectores, a través de una violencia extrema, la fragmentación de los textos, un lenguaje alterado y unos personajes monstruosos, con quienes la identificación se hace imposible puesto que no buscan la compasión pasiva sino una revulsión activa.

\section{Referencias}

Ampuero, M. F. (2018). Pelea de gallos. Madrid: Páginas de Espuma.

-. (3 de septiembre de 2019). María Fernanda Ampuero: 'El sentimiento más autodestructivo es querer que tus padres te quieran'. $B B C$ News. Entrevista por D. Massis. Recuperado de https://www.bbc.com/mundo/noticias-49349057.

-. (9 de abril de 2021). María Fernanda Ampuero: 'El monstruo es el síntoma de la sociedad'. Télam. Entrevista por D. Pruneda Paz. Recuperado de https://www.telam.com.ar/notas/202104/550250-ampuero-si-se-notara-que-quierogenerar-ideologia-mi-literatura-seria-una-basura.html. 
Butler, J. (2002). Cuerpos que importan. Sobre los límites materiales y discursivos del "sexo". A. Bixio (Trad.), Buenos Aires: Paidós.

-. (2006). Vida precaria. El poder del duelo y la violencia. F. Rodríguez (Trad.). Buenos Aires: Paidós.

- (2010). Marcos de guerra. Las vidas lloradas. (B. Moreno Carrillo, Trad.). Ciudad de México: Paidós.

Chakravorty Spivak, G. (2003). ¿Puede hablar el subalterno? Revista Colombiana de Antropología 39, 297-364.

https://doi.org/10.22380/2539472x.1244

- (2011). El nuevo subalterno: una entrevista silenciosa. En R. Rodríguez Freire (Ed.), La (re)vuelta de los estudios subalternos: una cartografía a (des)tiempo (pp. 358-378). Antofagasta, Chile: Qillqa.

Cixous, H. (1995). La risa de la medusa: Ensayos sobre literatura. A. M. Moix (Trad.), Barcelona: Anthropos.

Cohen, J. J. (1996). Monster Culture (Seven Theses). En Monster Theory: Reading Culture (pp. 3-25). Minneapolis: University of Minnesota Press. https://doi.org/10.5749/j.ctttsq4d.4

Derrida, J. (1998). Lingüística y gramatología I, O. Del Barco y C. Ceretti (Trads.). En De la gramatología (pp. 37-57). Ciudad de México: Siglo XXI.

Galindo Núñez, M. A. (2021). Inocencia quebrantada. El uso de lo grotesco en Pelea de Gallos de María Fernanda Ampuero. Sincronía 79, 334-344. https://doi.org/10.32870/sincronia.axxv.n79.18a21

Giorgi, G., y Rodríguez F. (Eds.). (2007). Ensayos sobre biopolítica. Excesos de vida. Buenos Aires: Paidós.

Guha, R. (2011). Prefacio a los Estudios Subalternos. En R. Rodríguez Freire (Ed.), La (re)vuelta de los estudios subalternos: una cartografía a (des)tiempo (pp. 69-70). Antofagasta, Chile: Qillqa.

Huet, M. H. (1993). Monstrous Immagination. Cambridge, Mass: Harvard University Press.

Jeftanovic, A. (2011). ¿De quién son los niños?: un cuerpo en disputa entre el Estado, la familia, la ley y el mercado. En A. Jeftanovic et al., Hablan los hijos. Discursos y estéticas de la perspectiva infantil en la literatura contemporánea (pp. 21-37). Santiago, Chile: Editorial Cuarto Propio.

Jeftanovic, A., y Pérez M. B. (2011). Cuerpos menores en el latifundio chileno: pobreza y abuso sexual en Hasta ya no ir de Beatriz García-Huidobro. En A. Jeftanovic et al., Hablan los hijos. Discursos y estéticas de la perspectiva infantil en la literatura contemporánea (pp. 85-100). Santiago, Chile: Editorial Cuarto Propio

Kristeva, J. (2006). Sobre la abyección. En Poderes de la perversión. Ensayo sobre LouisFerdinand Céline (pp. 7-47). Ciudad de México: Siglo XXI.

Lacan, J. (2003). La familia. V. Fishman (Trad.). Buenos Aires, Argentina: Editorial Argonauta.

Negri, A. (2007). Monstruo político. Vida desnuda y potencia. En G. Giorgi y F. Rodríguez (Eds.), Deleuze, Gilles, y otros. Ensayos sobre biopolítica. Excesos de vida. J. Ferreira y G. Giorgi (Trads.)(pp. 93-141). Buenos Aires: Paidós.

Ovejero, J. (16 de septiembre de 2015). Ocho escritoras feroces. Jot Down. Contemporary Culture Mag. Recuperado de: https://www.jotdown.es/2015/09/ocho-escritoras-feroces/.

Rodríguez Freire, R. (2011). 'Estudios Subalternos revoluciona la historia ('tercermundista'): notas sobre la insurgencia académica". En La (re)vuelta de los estudios subalternos: una cartografía a (des)tiempo (pp. 13-66). Antofagasta, Chile: Qillqa. 